\title{
Methotrexate resistance in relation to treatment outcome in childhood acute lymphoblastic leukemia
}

Anna Wojtuszkiewicz' , Godefridus J. Peters ${ }^{3}$, Nicole L. van Woerden ${ }^{1}$, Boas Dubbelman ${ }^{1}$, Gabriele Escherich ${ }^{6}$, Kjeld Schmiegelow ${ }^{7,8}$, Edwin Sonneveld ${ }^{9}$, Rob Pieters ${ }^{9,10}$, Peter M. van de Ven ${ }^{4}$, Gerrit Jansen ${ }^{5}$, Yehuda G. Assaraf ${ }^{11}$, Gertjan J. L. Kaspers ${ }^{1}$ and Jacqueline Cloos $^{1,2^{*}}$

\begin{abstract}
Background: Methotrexate (MTX) eradicates leukemic cells by disrupting de novo nucleotide biosynthesis and DNA replication, resulting in cell death. Since its introduction in 1947, MTX-containing chemotherapeutic regimens have proven instrumental in achieving curative effects in acute lymphoblastic leukemia (ALL). However, drug resistance phenomena pose major obstacles to efficacious ALL chemotherapy. Moreover, clinically relevant molecular mechanisms underlying chemoresistance remain largely obscure. Several alterations in MTX metabolism, leading to impaired accumulation of this cytotoxic agent in tumor cells, have been classified as determinants of MTX resistance. However, the relation between MTX resistance and long-term clinical outcome of ALL has not been shown previously.
\end{abstract}

Methods: We have collected clinical data for 235 childhood ALL patients, for whom samples taken at the time of diagnosis were also broadly characterized with respect to MTX resistance. This included measurement of concentrations of MTX polyglutamates in leukemic cells, mRNA expression of enzymes involved in MTX metabolism (FPGS, FPGH, RFC, DHFR, and TS), MTX sensitivity as determined by the TS inhibition assay, and FPGS activity.

Results: Herein we demonstrate that higher accumulation of long-chain polyglutamates of MTX is strongly associated with better overall (10-year OS: 90.6 vs $64.1 \%, P=0.008)$ and event-free survival (10-year EFS: 81.2 vs $57.6 \%, P=0.029)$ of ALL patients. In addition, we assessed both the association of several MTX resistance-related parameters determined in vitro with treatment outcome as well as clinical characteristics of pediatric ALL patients treated with MTX-containing combination chemotherapy. High MTX sensitivity was associated with DNA hyperdiploid ALL $(P<0.001)$, which was linked with increased MTX accumulation ( $P=0.03)$ and elevated reduced folate carrier (RFC) expression $(P=0.049)$ in this subset of ALL patients. TEL-AML1 fusion was associated with increased MTX resistance $(P=0.023)$. Moreover, a low accumulation of MTX polyglutamates was observed in MLL-rearranged and TEL-AML1 rearranged ALL $(P<0.05)$.

Conclusions: These findings emphasize the central role of MTX in ALL treatment thereby expanding our understanding of the molecular basis of clinical differences in treatment response between ALL individuals. In particular, the identification of patients that are potentially resistant to MTX at diagnosis may allow for tailoring novel treatment strategies to individual leukemia patients.

Keywords: Acute lymphoblastic leukemia, Antifolate, Methotrexate, Drug resistance, Hyperdiploid, FPGS, DHFR, RFC, TS

\footnotetext{
*Correspondence: j.cloos@vumc.nl

'Department of Pediatric Oncology/Hematology, VUmc Cancer Center Amsterdam, VU University Medical Center, Room CCA 4.28, De Boelelaan 1117, 1081HV Amsterdam, The Netherlands

${ }^{2}$ Department of Hematology, VU University Medical Center, Amsterdam, The Netherlands

Full list of author information is available at the end of the article
} 


\section{Background}

The treatment outcome of pediatric acute lymphoblastic leukemia (ALL) has greatly improved over the past seven decades with the current regimens resulting in a 5-year event-free survival (EFS) of around $80 \%$ [1-3]. This impressive improvement has been largely attributed to novel prognostic factors, including cytogenetic abnormalities such as TEL-AML1 and E2A-PBX1 gene fusions associated with good prognosis as well as $M L L$ gene rearrangements that confer unfavorable prognosis $[4,5]$. Yet, the high cure rates achieved with current treatment protocols are still paralleled by approximately $20 \%$ risk of relapse, which is consequently associated with poor prognosis [2, 3]. The emergence of relapse is largely attributable to drug resistance phenomena of leukemic cells. Thus, further advances in understanding the molecular basis underlying these drug resistance phenomena as well as accurate prediction of chemotherapy resistance prior to drug treatment may pave the way to overcoming chemoresistance.

Historically, one of the backbones of contemporary ALL treatment is the folate antimetabolite-methotrexate (MTX) [6]. Folates are essential enzyme cofactors involved in one-carbon metabolism, which includes several cellular biosynthetic pathways including thymidylate and de novo purine biosynthesis, amino acid metabolism, and mitochondrial protein synthesis [7]. Antifolates potently inhibit several folate-dependent enzymes engaged in nucleotide biosynthesis, which leads to cessation of DNA replication eventually resulting in cell death [6]. High-dose (HD)MTX is used as part of the central nervous system (CNS)directed therapy (intrathecal MTX), and MTX is an essential component of the maintenance treatment [1]. MTX is predominantly taken up into cells via the reduced folate carrier (RFC/SLC19A1), and in the case of HD-MTX treatment, also by passive diffusion across cellular membranes, at least to some extent $[8,9]$. Upon entry into the cytoplasm, MTX undergoes polyglutamylation-a unique metabolic conversion catalyzed by folylpolyglutamate synthetase (FPGS) [9]. This polyglutamylation, which is based on the sequential addition of multiple glutamate residues to the $\gamma$-carboxyl group of both folates and MTX, ensures efficient intracellular retention as well as sustains and enhances target enzyme inhibition [10-12]. The main targets of polyglutamylated MTX are dihydrofolate reductase (DHFR - also inhibited by MTX monoglutamates), thymidylate synthase (TS), and several enzymes involved in purine synthesis [9]. On the other hand, a lysosomal glycoprotein-folylpolyglutamate hydrolase (FPGH) - can counteract polyglutamylation, thereby increasing the efflux of MTX by the efflux transporters of the ATPbinding cassette superfamily including for example ABCC1 and ABCG2 [9, 13, 14]. Overall, the intracellular accumulation of MTX polyglutamates in leukemic cells proved to be an important determinant of the antileukemic activity of MTX in childhood ALL patients in vivo [15-17]. At the same time, high concentration of long-chain but not total MTX polyglutamates was associated with inhibition of de novo purine synthesis [15]. Consequently, a spectrum of alterations in MTX metabolism resulting in its decreased cellular accumulation has been identified to induce MTX resistance and compromise its curative effect. MTX resistance has been attributed to inactivating mutations or down-regulation affecting the $R F C$ gene as well as increased levels of DHFR and TS enzymes together with mutations that decrease their affinity for antifolates $[8,9,18-21]$. In addition, different polymorphisms in $R F C, T S$, and DHFR were previously reported, several of which were related to increased risk of relapse [22-24]. The cytotoxic effect elicited by MTX is also largely influenced by FPGS activity. Consequently, loss of FPGS function is a well established mechanism of resistance to MTX and other polyglutamylation-dependent antifolates in leukemic cells [17, 25-28]. Differential MTX sensitivity was shown to be associated with several cytogenetic abnormalities. Precursor B cell ALL displaying TEL-AML1 or $E 2 A-P B X 1$ gene fusions were characterized by decreased levels of MTX polyglutamates as compared to precursor B cell ALL with normal karyotype [16], while patients with hyperdiploid karyotype were highly sensitive to MTX $[29,30]$. Next, to its own cytotoxic effect, MTX is also important in the metabolism of other chemotherapeutics, such as mercaptopurine, used routinely in ALL treatment. MTX was shown to promote the conversion of mercaptopurine to one of its active metabolites-thioguanine nucleotides [31,32] — of which high concentration in leukemic cells was associated with increased EFS in leukemia patients [33]. Therefore, it is imperative to characterize the extent of resistance to this important chemotherapeutic as well as the mechanisms underlying this phenomenon.

The aim of the current study was therefore to determine which parameters of MTX resistance are related to the long-term clinical outcome in childhood ALL patients treated with combination chemotherapy. Towards this goal, we have determined a range of in vitro parameters associated with MTX resistance in a large cohort of pediatric ALL patients and subsequently assessed their relation with treatment outcome as well as with clinical characteristics.

\section{Results}

The association of ex vivo MTX resistance and the clinical outcome

To assess the relevance of MTX resistance in pediatric ALL, we determined several ex vivo parameters characterizing MTX metabolism in leukemic blasts of ALL patient specimens. This primarily included the measurement of 
the cellular concentration of total (1-6 glutamate residues) as well as long-chain (4-6 glutamate residues) MTX polyglutamates and the extent of TS inhibition (thymidylate synthase inhibition assay (TSIA)). For the TSIA parameter, we used both a continuous (TSIA cont.) and a short-term (TSIA short) exposure to MTX, followed by a drug-free period. TSIA cont. represents the overall ability of cells to accumulate MTX, while TSIA short enables the efflux of MTX during the drug-free period and hence rather points to the polyglutamylation capacity of the cells. This approach reliably reflects MTX sensitivity of leukemic blasts [34]. In addition, FPGS activity and mRNA expression of enzymes and proteins involved in MTX metabolism and transport were determined including DHFR, TS, FPGS, FPGH, and RFC. The abovementioned parameters were determined in a cohort of 235 samples derived from pediatric ALL patients at diagnosis. The patients under study were enrolled in several treatment protocols. The proportion of patients assigned to specific protocols along with their clinical characteristics is listed in Additional file 1: Table S1. Due to logistic challenges and leukemic blast number limitations, none of the MTX-related parameters could be measured in all the patients in our cohort. Therefore,

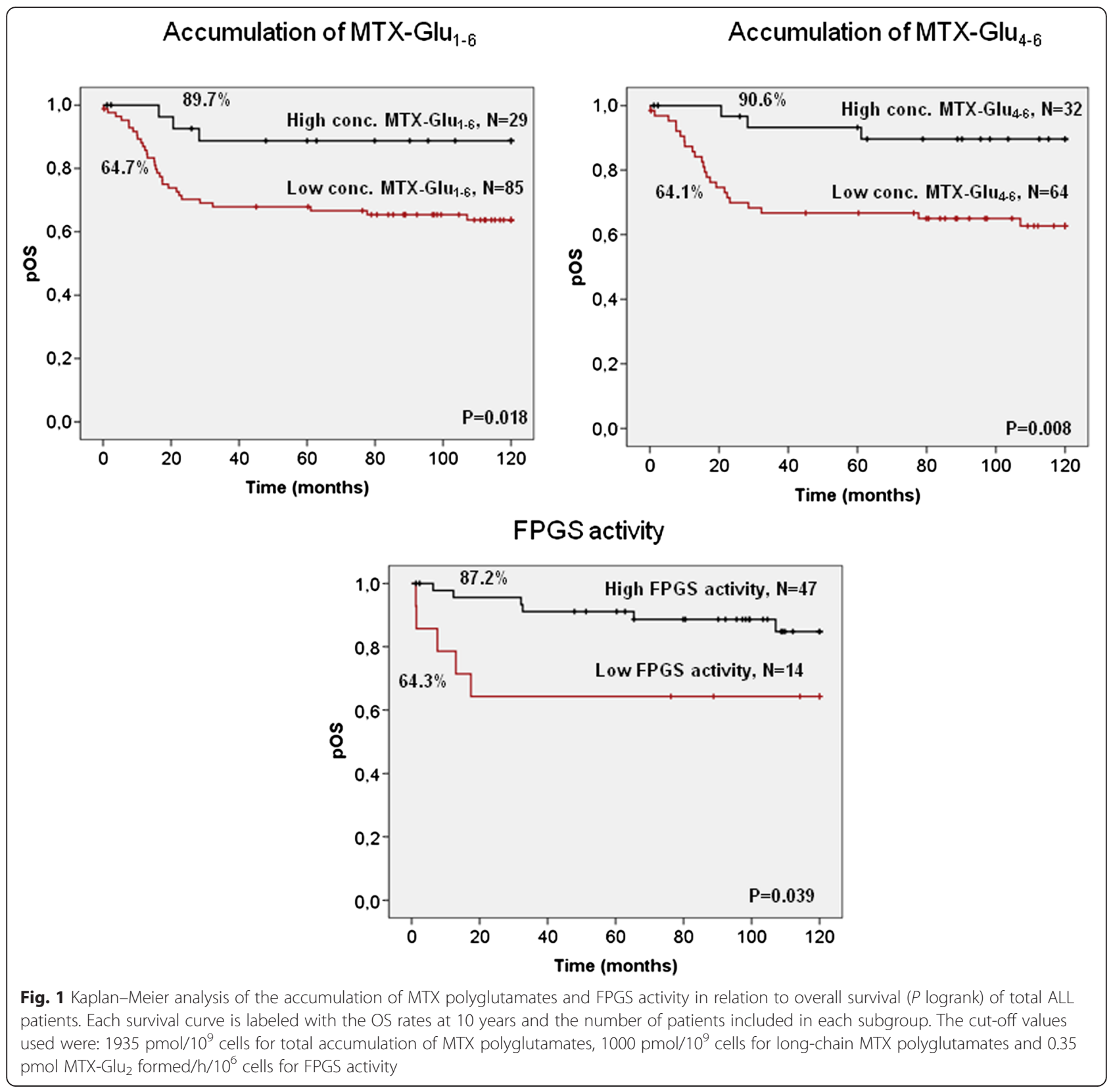



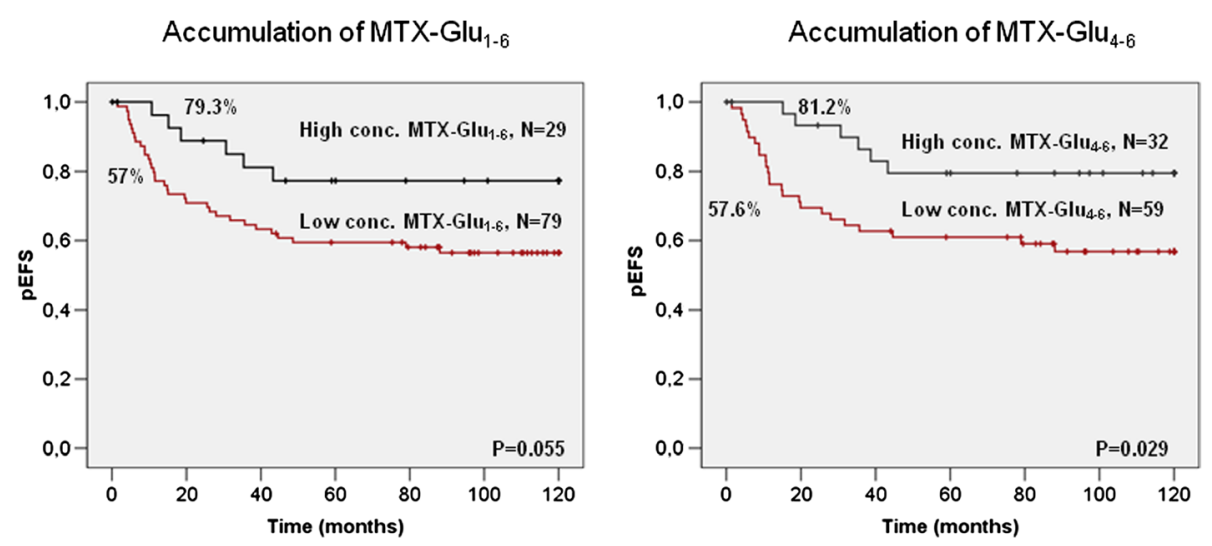

Fig. 2 Kaplan-Meier analysis of the accumulation of MTX polyglutamates in relation to event-free survival ( $P$ logrank). Each survival curve is labeled with the EFS rates at 10 years and the number of patients included in each subgroup. The cut-off values used were 1935 pmol/10 ${ }^{9}$ cells for total accumulation of MTX polyglutamates and 1000 pmol/10 9 cells for long-chain MTX polyglutamates

the number of cases included in the statistical analysis varied considerably for the different parameters and the number of patients used for each measurement as listed in the various tables.

The prognostic value of MTX resistance associated parameters was assessed with respect to long-term overall survival (OS) as well as EFS of childhood ALL patients. We identified three MTX-related variables that were significantly associated with OS in Kaplan-Meier analysis (Fig. 1). Higher levels of both the total concentration of cellular MTX as well as long-chain MTX polyglutamates were predictive of a better outcome. A 10-year OS reached $89.7 \%$ in patients with high concentrations of total MTX polyglutamates and $90.6 \%$ in case of longchain MTX polyglutamates, compared to $64 \%$ in patients with low levels of these MTX metabolites $(P=0.018$ for total concentration and $P=0.008$ for long-chain MTX polyglutamates, respectively). Consistently, higher FPGS activity was also predictive of a better OS $(P=0.039)$. For EFS, only the accumulation of long-chain MTX polyglutamates was a significant predictor of a better outcome (Fig. 2; $P=0.029$ ). The total concentration of MTX showed a similar trend, although it did not reach significance (Fig. $2, P=0.055$ ). The univariate Cox regression model further confirmed the concentration of both long-chain (EFS: $\mathrm{HR}=2.61, P=0.035$, OS: $\mathrm{HR}=4.44$, $P=0.015)$ and total MTX polyglutamates (EFS: HR = 2.29, $P=0.062$, OS: HR $=3.8, P=0.028)$ as the strongest prognostic variables (Table 1 and Additional file 1: Table S2). Due to the large heterogeneity of treatment protocols applied in therapy of the patients under study, we performed our analyses both with and without the correction for the treatment protocol. In this analysis, the concentration of the long-chain MTX polyglutamates was still significantly associated with OS $(\mathrm{HR}=3.82, P=0.03)$ but not with $\mathrm{EFS}(\mathrm{HR}=2.23$,
$P=0.084$ ), whereas the levels of total MTX polyglutamates were not significant for both the EFS and OS (EFS: $\mathrm{HR}=1.73, P=0.232$, OS: $\mathrm{HR}=2.57, P=0.125)$. Intriguingly, low RFC mRNA expression was a significant predictor of a longer EFS when corrected for the treatment protocol $(\mathrm{HR}=0.15, P=0.009)$. Trends observed for the concentration of both the total as well as long-chain MTX polyglutamates in the whole patient cohort were also apparent when precursor B cell ALL patients were analyzed separately (data not shown), while the numbers of $\mathrm{T}$ cell ALL patients were too low for further analysis.

Next, the independent prognostic values of the concentration of total as well as long-chain MTX polyglutamates were examined in the multivariate Cox regression model, in combination with clinical factors significantly associated with the EFS (white blood cell count-WBC, age, and CNS involvement-see Additional file 1: Tables S3 and S4) and OS (WBC, age, CNS involvement, lineage, and DNA index). Neither of the parameters tested had independent prognostic value in the multivariate analysis of EFS (Additional file 1: Table S5), both with (HR $=1.65, P=0.292$ for the total MTX polyglutamates, $\mathrm{HR}=2.16, P=0.112$ for the long-chain MTX polyglutamates) and without the correction for treatment protocol $(\mathrm{HR}=1.9, P=0.170$ for the total MTX polyglutamates, $\mathrm{HR}=2.33, P=0.073$ for the long-chain MTX polyglutamates). RFC mRNA expression showed a significant association with $O S$ in the multivariate analysis both with $(\mathrm{HR}=0.18, P=0.025)$ and without $(\mathrm{HR}=0.13, P=0.026)$ the correction for the treatment protocol. As in the univariate analysis, low RFC expression was predictive of a better OS which is the opposite of what was expected. Neither the accumulation of the total nor the long-chain MTX polyglutamates showed significant association with the OS (Additional file 1: Table S6). 
Table 1 Results of univariate Cox regression model of MTX resistance-related variables in relation to event-free survival

\begin{tabular}{|c|c|c|c|c|c|c|}
\hline & \multicolumn{3}{|c|}{ Not corrected for protocols } & \multicolumn{3}{|c|}{ Corrected for protocols } \\
\hline & $\bar{N}$ & Hazard ratio $(95 \% \mathrm{Cl})$ & $P$ value & $N$ & Hazard ratio $(95 \% \mathrm{Cl})$ & $P$ value \\
\hline \multicolumn{7}{|c|}{ TSIA short (cut-off $1.44 \mu \mathrm{M})$} \\
\hline Low & 79 & 1.00 & & 73 & 1.00 & \\
\hline High & 23 & 1. $39(0.67-2.89)$ & 0.374 & 22 & $1.34(0.60-3.01)$ & 0.477 \\
\hline \multicolumn{7}{|c|}{ TSIA continuous (cut-off $0.035 \mu \mathrm{M}$ ) } \\
\hline Low & 25 & 1.00 & & 22 & 1.00 & \\
\hline High & 75 & $1.19(0.54-2.60)$ & 0.671 & 70 & $1.3(0.53-3.18)$ & 0.567 \\
\hline \multicolumn{7}{|c|}{ MTX-Glu ${ }_{1-6}$ accumulation (cut-off 1935 pmol/109 cells) } \\
\hline High & 29 & 1.00 & & 29 & 1.00 & \\
\hline Low & 79 & $2.29(0.96-5.45)$ & 0.062 & 72 & $1.73(0.70-4.27)$ & 0.232 \\
\hline \multicolumn{7}{|c|}{ MTX-Glu L-6 accumulation (cut-off 1000 pmol/109 cells) } \\
\hline High & 32 & 1.00 & & 32 & 1.00 & \\
\hline Low & 59 & $2.61(1.07-6.36)$ & $0.035^{*}$ & 56 & $2.23(0.90-5.57)$ & 0.084 \\
\hline \multicolumn{7}{|c|}{ DHFR mRNA (cut-off 3.74) } \\
\hline High & 27 & 1.00 & & 27 & 1.00 & \\
\hline Low & 18 & $1.50(0.50-4.47)$ & 0.466 & 18 & $1.16(0.37-3.67)$ & 0.796 \\
\hline \multicolumn{7}{|c|}{ TS mRNA (cut-off 10) } \\
\hline Low & 34 & 1.00 & & 33 & 1.00 & \\
\hline High & 12 & $0.77(0.21-2.81)$ & 0.696 & 12 & $0.78(0.21-3.22)$ & 0.781 \\
\hline \multicolumn{7}{|c|}{ FPGS mRNA (cut-off 4.13) } \\
\hline High & 19 & 1.00 & & 19 & 1.00 & \\
\hline Low & 23 & $1.17(0.36-3.83)$ & 0.798 & 22 & $0.58(0.16-2.18)$ & 0.421 \\
\hline \multicolumn{7}{|c|}{ FPGH mRNA (cut-off 3.17) } \\
\hline High & 16 & 1.00 & & 15 & 1.00 & \\
\hline Low & 18 & $1.18(0.32-4.40)$ & 0.805 & 18 & $0.80(0.19-3.33)$ & 0.764 \\
\hline \multicolumn{7}{|c|}{ RFC mRNA (cut-off 0.86) } \\
\hline High & 19 & 1.00 & & 19 & 1.00 & \\
\hline Low & 25 & $0.70(0.23-2.19)$ & 0.544 & 24 & $0.36(0.10-1.32)$ & 0.123 \\
\hline \multicolumn{7}{|c|}{ FPGS activity (cut-off 0.35) } \\
\hline High & 48 & 1.00 & & 48 & 1.00 & \\
\hline Low & 12 & $2.32(0.79-6.80)$ & 0.125 & 11 & $2.61(0.88-7.76)$ & 0.084 \\
\hline
\end{tabular}

TSIA continuous and short-term exposure (TSIA short) are expressed as the concentration of MTX (in $\mu \mathrm{M}$ ) necessary to inhibit $50 \%$ of the TS activity (TSI ${ }_{50}$ ) compared to the controls incubated without MTX (in triplicate); the concentration of MTX polyglutamates (MTX-Glu 1-6 and MTX-Glu M $_{-6}$ ) is expressed as pmol MTX-Glu $n / 10^{9}$ cells; mRNA expression of folate enzymes is expressed as ratio normalized to $\beta$-actin; FPGS activity is expressed as pmol MTX-Glu ${ }_{2}$ formed/h/10 $0^{6}$ cells. The asterisk denotes significant associations

Ex vivo MTX resistance in pediatric ALL patient specimens To substantiate the associations found in the clinical outcome analysis, we performed a more in-detail characterization of MTX resistance in the patient cohort under study. Since, precursor B cell ALL and T cell ALL have a different MTX response, we first compared the distribution of the MTX-resistance parameters between these two subtypes of ALL (Table 2). Indeed, our results support previously reported findings in a patient group partially overlapping with the currently analyzed cohort
[17, 34, 35]. Accordingly, precursor B cell ALL patient specimens showed higher MTX sensitivity than $\mathrm{T}$ cell ALL samples, as determined by lower median $\mathrm{TSI}_{50}$ values for the short-term exposure (3.9-fold difference in the median, $P<0.001$ ), as well as higher accumulation of both total and long-chain MTX polyglutamates (1.9-fold and 3.3-fold, respectively, $P<0.001)$. These differences were paralleled by higher mRNA expression (2.6-fold, $P=0.008)$ and enzyme activity (5.6-fold, $P<0.001)$ of FPGS in precursor B cell ALL as well as elevated levels 
Table 2 MTX resistance-related variables in precursor B and T cell ALL

\begin{tabular}{|c|c|c|c|c|c|}
\hline & \multicolumn{2}{|c|}{ Precursor B cell ALL } & \multicolumn{3}{|c|}{ T cell ALL } \\
\hline & $\bar{N}$ & Median (range) & $N$ & Median (range) & $P$ value \\
\hline TSIA cont. & 85 & $0.058(0.01-0.76)$ & 30 & $0.062(0.01-0.22)$ & 0.595 \\
\hline TSIA short & 87 & $0.37(0.16-12.97)$ & 30 & $1.44(0.16-40.0)$ & $<0.001$ \\
\hline MTX-Glu & 97 & $1210(120-4838)$ & 31 & $630(314-1943)$ & $<0.001$ \\
\hline MTX-Glu & 83 & $856(80-3190)$ & 25 & $260(0-843)$ & $<0.001$ \\
\hline DHFR mRNA & 37 & $3.86(0.27-55.06)$ & 17 & $12.42(1.48-34.11)$ & $<0.001$ \\
\hline TS mRNA & 37 & $2.64(0.24-23.04)$ & 18 & $10.26(1.64-25.04)$ & $<0.001$ \\
\hline FPGS mRNA & 32 & $6.26(1.12-39.64)$ & 20 & $2.39(0.52-17.20)$ & 0.008 \\
\hline FPGH mRNA & 27 & $2.12(0.16-18.00)$ & 16 & $4.83(0.18-27.65)$ & 0.196 \\
\hline RFC mRNA & 35 & $0.89(0.24-6.90)$ & 20 & $0.79(0.23-4.79)$ & 0.668 \\
\hline FPGS activity & 57 & $1.01(0.03-11.33)$ & 16 & $0.18(0.02-1.57)$ & $<0.001$ \\
\hline
\end{tabular}

$P$ value is determined by the Mann-Whitney $U$ test; TSIA continuous (TSIA cont.) and short-term exposure (TSIA short) are expressed as the concentration of MTX (in $\mu \mathrm{M}$ ) necessary to inhibit $50 \%$ of the TS activity $\left(\mathrm{TSI}_{50}\right.$ ) compared to the controls incubated without MTX (in triplicate); the concentration of MTX polyglutamates (MTX-Glu ${ }_{1-6}$ and MTX-Glu ${ }_{4-6}$ ) are expressed as pmol MTX-Glu $\mathrm{u}_{\mathrm{n}} / 10^{9}$ cells; mRNA expression of folate enzymes is expressed as ratio normalized to $\beta$-actin; FPGS activity is expressed as pmol MTX-Glu formed $/ \mathrm{h} / 10^{6}$ cells

of DHFR and TS mRNA in T cell ALL (3.2-fold and 3.9-fold, respectively, both $P<0.001$ ).

Next, in order to determine which variables strongly influence MTX resistance in ALL patients, we examined the correlation between cellular levels of MTX polyglutamates, activities, and mRNA expression levels of MTX metabolic enzymes with in vitro MTX sensitivity as determined by the TSIA. In line with previous findings [34], both the TSIA results based on continuous and the short-term MTX exposure correlated with concentrations of total (TSIA continuous: $R=-0.432$ and TSIA short-term: $R=-0.524, P<0.001)$ and long-chain MTX polyglutamates (Table $3, R=-0.399, P=0.001$ and $R=-0.568, P<0.001)$ as well as with the TS mRNA expression (TSIA continuous: $R=0.466, P=$ 0.033 and TSIA short-term: $R=0.693, P=0.001$ ). Similar correlations were obtained when precursor $B$ cell patients were examined separately. Weaker and nonsignificant correlations were found in T cell ALL, suggesting that there might be a substantial difference between the factors determining MTX resistance in precursor B cell and T cell leukemia. To formally test whether the strength of association between TSIA and MTX polyglutamates or TS mRNA expression differed between $\mathrm{B}$ cell and $\mathrm{T}$ cell leukemia, we used a linear regression model that included an interaction between the level of MTX polyglutamates and the lineage. No significant difference in association between the concentration of MTX polyglutamylates and both the continuous and short-term TSIA was found between the precursor B cell and T cell ALL (data not shown).

Intriguingly, the accumulation of both total and longchain MTX polyglutamates correlated with FPGS activity but not with its mRNA levels (Table 4). This association was observed for the whole cohort as well as for precursor B cell ALL alone. Consequently, FPGS mRNA expression did not correlate with FPGS activity $(P=0.125$ for the whole cohort, $P=0.75$ for precursor B cell ALL, and $P=0.544$ for $\mathrm{T}$ cell ALL).

Table 3 Correlation of the TSIA assay (continuous and short exposure) with accumulation of MTX polyglutamates and TS mRNA expression

\begin{tabular}{|c|c|c|c|c|c|c|}
\hline & \multicolumn{2}{|c|}{ Precursor B cell ALL } & \multicolumn{2}{|l|}{ T cell ALL } & \multicolumn{2}{|l|}{ Total ALL } \\
\hline & TSIA cont. & TSIA short & TSIA cont. & TSIA short & TSIA cont. & TSIA short \\
\hline \multicolumn{7}{|l|}{ MTX-Glu } \\
\hline Correlation coefficient & $-0.547^{*}$ & $-0.495^{*}$ & -0.094 & -0.128 & $-0.432^{*}$ & $-0.524^{*}$ \\
\hline$P$ value & $<0.001$ & $<0.001$ & 0.685 & 0.612 & $<0.001$ & $<0.001$ \\
\hline Number of patients & 64 & 58 & 21 & 18 & 85 & 76 \\
\hline \multicolumn{7}{|l|}{ MTX-Glu } \\
\hline Correlation coefficient & $-0.494^{*}$ & $-0.503^{*}$ & -0.258 & 0.046 & $-0.399^{*}$ & $-0.568^{*}$ \\
\hline$P$ value & $<0.001$ & $<0.001$ & 0.336 & 0.875 & 0.001 & $<0.001$ \\
\hline Number of patients & 54 & 50 & 16 & 14 & 70 & 64 \\
\hline \multicolumn{7}{|l|}{ TS mRNA } \\
\hline Correlation coefficient & 0.591 & $0.678^{*}$ & 0.139 & 0.483 & $0.466^{*}$ & $0.693^{*}$ \\
\hline$P$ value & 0.056 & 0.045 & 0.701 & 0.187 & 0.033 & 0.001 \\
\hline Number of patients & 11 & 9 & 10 & 9 & 21 & 18 \\
\hline
\end{tabular}

$P$ value was estimated using Spearman's Rho test; TSIA continuous (TSIA cont.) and short-term exposure (TSIA short) are expressed as the concentration of MTX (in $\mu \mathrm{M})$ necessary to inhibit $50 \%$ of the TS activity $\left(\mathrm{TSI}_{50}\right)$ compared to the controls incubated without MTX (in triplicate); the concentration of MTX polyglutamates (MTX-Glu ${ }_{1-6}$ and MTX-Glu $u_{-6}$ ) is expressed as pmol MTX-Glu $n$ / $10^{9}$ cells; TS mRNA level is expressed as ratio normalized to $\beta$-actin. The asterisk denotes significant $(P<0.05)$ associations 
Table 4 Correlation of cellular MTX polyglutamate levels with mRNA expression of FPGS and FPGH as well as FPGS activity

\begin{tabular}{|c|c|c|c|c|c|c|}
\hline & \multicolumn{2}{|c|}{ Precursor B cell ALL } & \multicolumn{2}{|l|}{ T cell ALL } & \multicolumn{2}{|l|}{ Total ALL } \\
\hline & MTX-Glu & MTX-Glu & MTX-Glu & MTX-Glu $4-6$ & MTX-Glu & MTX-Glu \\
\hline \multicolumn{7}{|l|}{ FPGS mRNA } \\
\hline$R$ & -0.168 & -0.082 & 0.345 & 0.002 & 0.264 & 0.280 \\
\hline$P$ value & 0.456 & 0.724 & 0.176 & 0.994 & 0.104 & 0.104 \\
\hline Number of patients & 22 & 21 & 17 & 14 & 39 & 35 \\
\hline \multicolumn{7}{|l|}{ FPGH mRNA } \\
\hline$R$ & 0.117 & 0.195 & 0.366 & 0.537 & 0.101 & 0.045 \\
\hline$P$ value & 0.622 & 0.424 & 0.219 & 0.110 & 0.576 & 0.817 \\
\hline Number of patients & 20 & 19 & 13 & 10 & 33 & 29 \\
\hline \multicolumn{7}{|l|}{ FPGS activity } \\
\hline$R$ & $0.429^{*}$ & $0.419^{*}$ & 0.265 & 0.05 & $0.522^{*}$ & $0.533^{*}$ \\
\hline$P$ value & 0.005 & 0.01 & 0.431 & 0.898 & $<0.001$ & $<0.001$ \\
\hline Number of patients & 41 & 37 & 11 & 9 & 52 & 46 \\
\hline
\end{tabular}

$R$ and Pvalues were estimated using Spearman's Rho test; the concentration of MTX polyglutamates (MTX-Glu ${ }_{1-6}$ and MTX-Glu an-6) is expressed as pmol MTX-Glu $\mathrm{n}_{\mathrm{n}} / 10^{9}$ cells; mRNA expression of folate enzymes is expressed as ratio normalized to $\beta$-actin; FPGS activity is expressed as pmol MTX-Glu $\mathrm{f}_{2}$ formed/h/10 ${ }^{6}$ cells. The asterisk denotes significant $(P<0.05)$ associations

\section{Ex vivo MTX resistance in association with chromosomal abnormalities}

Next, we examined the possible association of MTX resistance with the hyperdiploid karyotype as well as three other recurrent cytogenetic abnormalities seen in ALL: $M L L$ rearrangements, $T E L-A M L 1$, and $E 2 A-P B X 1$. We found that blasts of hyperdiploid ALL patients were significantly more sensitive to MTX than blasts from non-hyperdiploid ALL patients (Fig. 3), both in the continuous and the short-term TSIA $(P<0.001)$. Consistent with previous reports [30, 36], the leukemic blasts of these patients accumulated significantly higher levels of total MTX and in the same time displayed elevated RFC mRNA levels, confirming that increased uptake of MTX contributes to MTX hypersensitivity observed in this group.

Similarly, the analyzed cytogenetic subtypes of ALL showed several associations with MTX resistance-related parameters (Table 5). In line with findings from others [16], we established that TEL-AML1 fusion results in lower accumulation of both total and long-chain MTX polyglutamates (2.2-fold, $P=0.013$ and 2.8-fold, $P=0.007$, respectively). In addition, these patients showed higher $\mathrm{TSI}_{50}$ values for both continuous and short-term exposure (3.3-fold, $P=0.023$ and 2.9-fold $P=0.06$, respectively). Interestingly, ALL patients with $M L L$ rearrangements also displayed lower accumulation of total and long-chain MTX polyglutamates (3.6-fold, $P=0.005$ and 4.3-fold, $P=0.012$, respectively), however this was not paralleled by elevated $\mathrm{TSI}_{50}$ values. No significant correlations were observed for patients harboring the $E 2 A-P B X 1$ nor $B C R$ $A B L$ gene fusions, which can partially be explained by the small patient numbers in both groups.

\section{Discussion}

In the current study, which used multiple parameters associated with MTX sensitivity, we demonstrate that the cellular level of MTX-induced cytotoxicity is an important determinant of long-term treatment outcome in childhood ALL. We showed that accumulation of longchain MTX polyglutamates was the strongest MTX resistance-associated variable, as reflected by its significant association with both OS and EFS in the analyzed patient cohort. Our data support and further extend previous studies documenting better antileukemic effect of MTX as well as favorable 5-year EFS in childhood ALL patients, whose leukemic cells accumulated higher levels of MTX polyglutamates [15, 29, 37]. On the other hand, a study of the Children's Oncology Group (COG) suggested that the association between the concentration of MTX polyglutamates and EFS is abrogated by higher dose MTX therapy [38]. However, this study involved a different mode of MTX administration and cut-off levels for high/low polyglutamate accumulation, which might have influenced the different outcome of the analysis. When analyzed in multivariate Cox regression with correction for established clinical factors (including WBC, age, CNS involvement, lineage, and DNA index) as covariates, the cellular level of long-chain MTX polyglutamates was not an independent prognostic factor. This indicates that despite the important role in ALL treatment response, MTX polyglutamates may not have additional predictive value to the already existing models. Surprisingly, low levels of $R F C$ were predictive of a better overall survival in both univariate and multivariate analysis, contradicting previous reports [9, 39]. The relation between $R F C$ mRNA expression and overall 


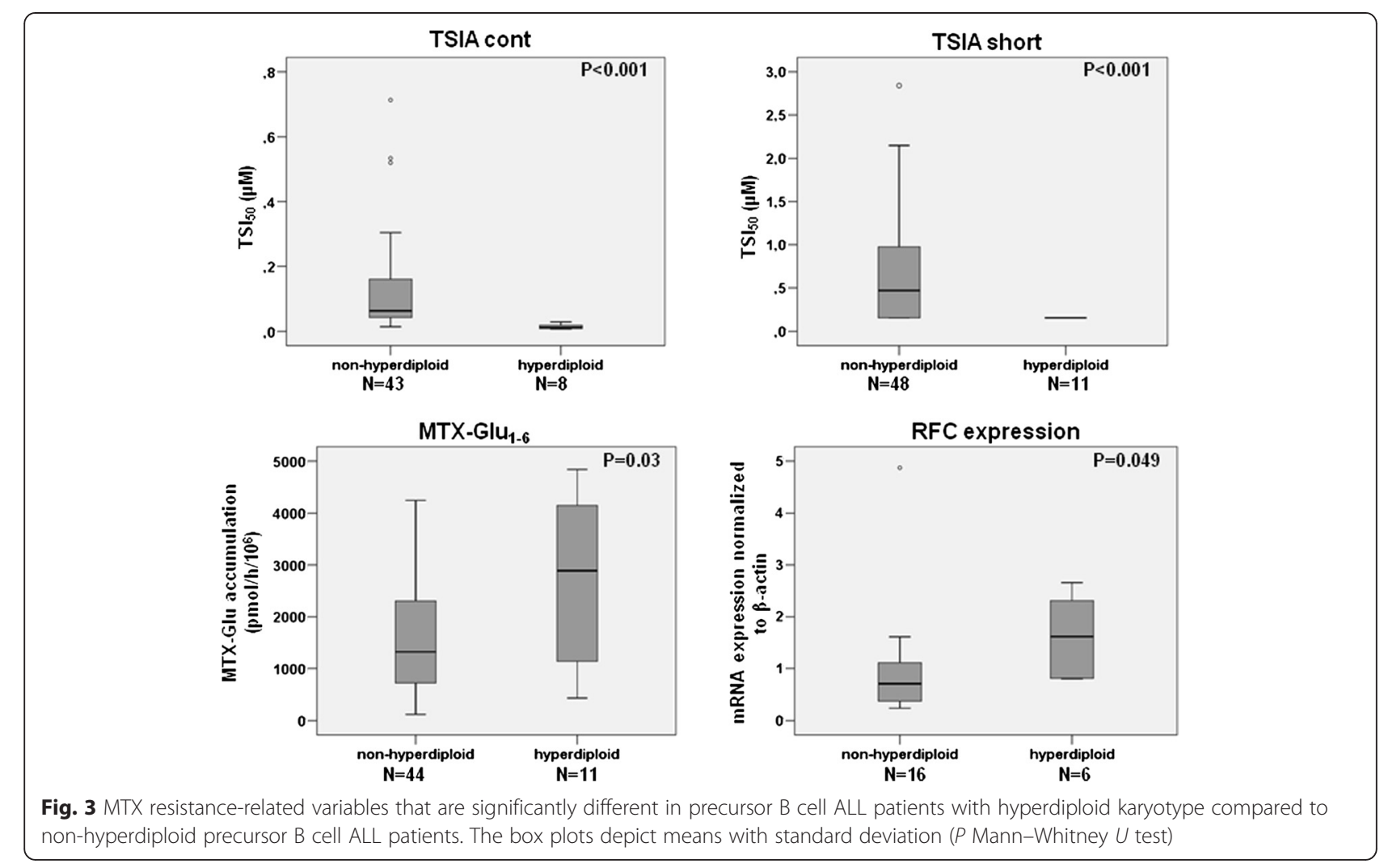

survival was the strongest when corrected for the treatment protocol, suggesting that it might be linked to high doses of MTX used in some treatment protocols. When examined within each treatment protocol separately, this association was only observed in patients treated at DCOG ALL8 protocol, on which patients depending on the risk group were administered MTX at $2 \mathrm{~g} / \mathrm{m}^{2}$ or $5 \mathrm{~g} /$ $\mathrm{m}^{2}$ [40]. In contrast, on COALL protocol ALL-97, for which this relation was absent, MTX was administered at $1 \mathrm{~g} / \mathrm{m}^{2}[2,41]$. This discrepancy may be explained by the limited number of patients treated with $1 \mathrm{~g} / \mathrm{m}^{2}$ in this cohort (6 patients for COALL-97 and 16 for DCOG ALL8). Decreased RFC expression as well as mutations in the $R F C$ gene resulting in less efficient uptake of antifolates by tumor cells, have been associated with MTX resistance $[9,39]$. On the other hand, some of the mutations found in the $R F C$ gene were previously reported to increase the affinity of RFC to folates, resulting in increased intracellular accumulation and competition of folate with MTX [42]. It is therefore possible that extremely high $R F C$ expression results in high concentration of folates in the cells, leading to decreased efficacy of MTX and worse treatment outcome. Unfortunately, the numbers of patients treated on the other protocols for which RFC mRNA expression data were available were too low to allow this analysis.
Moreover, we show that the lineage as well as a number of chromosomal abnormalities are associated with distinct levels of MTX sensitivity. In agreement with previous analysis in a partially overlapping patient cohort as well as in other studies [17, 34, 35], we observed here elevated accumulation of MTX polyglutamates together with decreased expression of DHFR and TS mRNA and consequently higher MTX sensitivity in precursor B cell ALL, as compared to T cell ALL. The difference in the accumulation of the long-chain MTX polyglutamates between these two distinct subtypes of ALL exceeded that obtained for the total MTX polyglutamates. This observation, together with the FPGS activity being significantly increased in the precursor B cell ALL, suggests that differences in MTX response between the precursor B cell and T cell leukemia are highly dependent on FPGS activity and consequent MTX polyglutamylation. Indeed, a previous study comparing lineage-based differences in MTX sensitivity in leukemia cell lines also pointed to the involvement of FPGS activity and DHFR levels [43]. The importance of the cellular accumulation of MTX polyglutamates was further corroborated by its association with the TSIA, which was previously shown to be a good determinant of MTX sensitivity, as reflected by the correlation between the TSIA results and MTX cytotoxicity [34]. This association was 
Table 5 MTX sensitivity and accumulation of MTX polyglutamates in relation to cytogenetic abnormalities

\begin{tabular}{|c|c|c|c|c|c|}
\hline & & TSIA cont. & TSIA short & MTX-Glu ${ }_{1-6}$ & MTX-Glu \\
\hline \multirow[t]{2}{*}{ Normal cytogenetics } & $N$ & 16 & 23 & 18 & 17 \\
\hline & Median (range) & $0.048(0.01-0.71)$ & $0.28(0.16-2.84)$ & $2102(436-4240)$ & $1514(209-3190)$ \\
\hline \multirow[t]{3}{*}{ MLL-rearranged } & $N$ & 8 & 6 & 4 & 3 \\
\hline & Median (range) & $0.06(0.03-0.16)$ & $0.21(0.16-1.33)$ & 591 (360-1016) & $350(280-443)$ \\
\hline & $P$ value & 0.610 & 0.896 & $0.005^{*}$ & $0.012^{*}$ \\
\hline \multirow[t]{3}{*}{$B C R-A B L$} & $N$ & 4 & 2 & 4 & 2 \\
\hline & Median (range) & $0.04(0.03-0.28)$ & - & $2088(360-3721)$ & $1630(1212-2047)$ \\
\hline & $P$ value & 0.750 & 0.240 & 0.712 & 0.749 \\
\hline \multirow[t]{3}{*}{ TEL-AML1 } & $N$ & 10 & 9 & 8 & 7 \\
\hline & Median (range) & $0.16(0.06-0.37)$ & $0.82(0.54-11.21)$ & 945 (290-2476) & $550(380-1152)$ \\
\hline & $P$ value & $0.023^{*}$ & 0.06 & $0.013^{*}$ & $0.007^{*}$ \\
\hline \multirow[t]{3}{*}{$E 2 A-P B X 1$} & $N$ & 3 & 3 & 1 & 0 \\
\hline & Median (range) & $0.14(0.05-0.29)$ & $0.77(0.57-1.12)$ & - & - \\
\hline & $P$ value & 0.254 & 0.157 & - & - \\
\hline
\end{tabular}

First, the Kruskal-Wallis analysis of variance was used to compare all the four groups, and variables with the $P$ value above 0.1 were further examined in detail. The Mann-Whitney $U$ test was used to compare MTX-related variables between each subgroup of ALL patients carrying certain cytogenetic abnormality and patients displaying normal karyotype as a reference group; TSIA continuous (TSIA cont.) and short-term exposure (TSIA short) are expressed as the concentration of MTX (in $\mu \mathrm{M}$ ) necessary to inhibit $50 \%$ of the TS activity $\left(\mathrm{TSI}_{50}\right.$ ) compared to the controls incubated without MTX (in triplicate); the concentration of MTX polyglutamates (MTX-Glu ${ }_{1-6}$ and MTX-Glu ${ }_{4-6}$ ) is expressed as pmol MTX-Glu $/ 10^{9}$ cells. The asterisk denotes significant $(P<0.05)$ associations

found in both the entire patient cohort as well as in precursor B cell ALL alone but not in T cell ALL when analyzed separately. The linear regression analysis did not show that the association of cellular MTX polyglutamate levels with the TSIA is actually different between precursor $\mathrm{B}$ cell and $\mathrm{T}$ cell leukemia. The apparent differences between the correlations may be due to a large uncertainty in the estimates for the correlations of the $\mathrm{T}$ cell ALL, which may have been caused by the small sample size for this subgroup. Taken together, our data indicate that despite the differences in concentration of MTX polyglutamates and MTX sensitivity profiles between precursor B cell and T cell ALL, the accumulation of MTX polyglutamates is likely an indicator of MTX resistance as determined by the TSIA in both of these ALL subtypes.

Intriguingly, in parallel to differences in both FPGS mRNA levels and activity observed between precursor B cell and T cell ALL, we found no correlation between FPGS mRNA level and enzyme activity or the concentration of MTX polyglutamates. This suggests that the level of FPGS mRNA might not directly translate to its enzymatic activity. A strong correlation was previously reported between FPGS mRNA expression and activity in leukemic cell lines [43]. In fact, our previous finding of the high propensity of human FPGS gene in ALL specimens to undergo impaired splicing is consistent with the fact that transcript levels may not correlate at all with FPGS catalytic activity [28, 44], Wojtuszkiewicz et al. unpublished observations. Moreover, decreased rates of FPGS mRNA translation affecting its activity were previously detected in murine leukemic cell lines selected with another polyglutamylation-dependent antifolate-edatrexate [45]. In addition, we have reported that aberrant FPGS splicing is a potential contributing factor to the loss of FPGS function, as various FPGS mRNA splicing alterations were detected in MTX-resistant leukemic cell lines devoid of FPGS activity as well as in adult ALL patient samples [28].

MTX sensitivity in the patient cohort under study differed between several genetic subtypes of precursor B cell ALL. This included the hyperdiploid patients, displaying high MTX sensitivity associated with increased RFC expression as well as TEL-AML1 fusion and $M L L$ rearrangements displaying an increased MTX resistance. Elevated RFC expression might be caused by an additional copy of RFC gene-carrying chromosome 21, which is often observed in hyperdiploid ALL. Our results support previous findings showing that hyperdiploid patients accumulate higher levels of MTX polyglutamates associated with elevated $R F C$ expression $[29,30]$. Consequently, this subset of patients responded favorably to MTX-containing chemotherapy as compared to patients with a non-hyperdiploid karyotype [37]. Although the remarkable sensitivity of hyperdiploid ALL cannot be entirely explained by high MTX sensitivity, the current results as well as observations of others $[29,30,37]$ suggest that it is an important biological feature contributing to sensitivity of this ALL subtype. Precursor B cell ALL with TEL-AML1 fusion as well as with rearranged $M L L$ gene were associated with lower accumulation of MTX polyglutamates, which in the case of TEL- 
AML1 was accompanied by increased MTX resistance as reflected by the TSIA. Precursor B cell ALL carrying either TEL-AML1 or E2A-PBX1 gene fusions was previously shown to accumulate decreased levels of MTX polyglutamates as compared to precursor B cell ALL which are devoid of these cytogenetic aberrations [16]. This was associated with diminished expression of RFC in E2APBX1 ALL and elevated expression of ABCG2-an MTX efflux transporter-in ALL patients with TEL-AML1 fusion [16]. Decreased RFC activity resulting from transcriptional silencing as well as mutations and allele loss was previously reported as the cause of antifolate resistance in several tumor types, including leukemia, breast cancer, and osteosarcoma [19-21]. Similar overexpression of ABC transporters is an established mechanism of antifolate resistance $[9,13,46]$. Moreover, another study suggests that both TEL-AML1 and E2A-PBX1 gene fusions downregulate FPGS expression by interacting with its promoter region $[47,48]$. Interestingly, TEL-AML1 and E2A-PBX1 are generally associated with a relatively good prognosis, as opposed to patients harboring rearranged $M L L$ gene [4], which can be explained by the differences in sensitivity to other chemotherapeutics between these ALL subtypes [5]. The numbers of ALL patients displaying these cytogenetic abnormalities for which MTX sensitivity-associated variables were measured was very limited in this study. Hence, we were not able to evaluate the role of particular trisomies (i.e., trisomy 21) across the patients with hyperdiploid karyotype or the analyzed cytogenetic abnormalities. Therefore, these associations should be further addressed in large future studies. However, the current data suggest that TEL-AML1, E2A-PBX1, and $M L L$-rearranged ALL may benefit from courses with high-dose MTX, partly overcoming the polyglutamylation and transport defects $[16,18]$.

One of the major limitations of the current study was the low numbers of patients for which particular parameters were recorded. This especially influenced analyses in various ALL groups, such as cytogenetic subtypes, where the patient numbers were extremely low. Moreover, patients included in this study were treated on diverse protocols with distinct MTX administration doses. This issue, however, was addressed in the statistical analysis by including the treatment protocol as a covariate. Finally, the lack of MTX-related toxicity data limited our insight into the associations of particular MTX resistancerelated parameters and the clinical outcome of ALL patients. These issues should be carefully considered in future studies.

\section{Conclusions}

Taken together, our study clearly shows that the low cellular level of long-chain polyglutamates of MTX is an important predictor of MTX resistance and is associated with dismal therapeutic outcome. Its additional prognostic value warrants further investigation in larger studies using more up-to-date treatment regimens. As MTX remains one of the mainstays of contemporary ALL treatments, expanding our understanding of its contribution to the treatment outcome is of supreme therapeutic value. In particular, the identification of patients that are potentially resistant to MTX at start of the treatment may allow for tailoring novel treatment strategies to individual leukemia patients in the context of combination chemotherapy.

\section{Materials and methods \\ ALL patients}

We analyzed a total of 235 newly diagnosed (see Additional file 1: Table S1 for patient characteristics), untreated pediatric ALL patients treated on Dutch Childhood Oncology Group (DCOG $N=125$ ) protocols ALL6-ALL9 [40, 49], German Co-operative ALL study group (COALL $N=93$ ) protocols 92-97 [2, 41] and Nordic Society of Paediatric Haematology and Oncology (NOPHO $N=17$ ) protocols ALL-92-ALL-2000 [50]. All patients (or parents or legal guardians of patients) have provided a written informed consent.

Immunophenotyping and DNA index flow cytometry were performed at reference laboratories of the participating groups; patient characteristics were collected by the study centers.

For all patients, leukemic cells freshly obtained from the bone marrow or peripheral blood of ALL patients at diagnosis were isolated within $48 \mathrm{~h}$ of sampling as described previously [51]. When necessary, contaminating normal cells were removed by monoclonal antibodies linked to magnetic beads as described previously [52]. All samples contained $>80 \%$ leukemic blasts with the majority of samples reaching blast percentages around $90 \%$ (only 11 out of 235 patient samples contained $<85 \%$ blasts), as determined by cytospin preparations stained with May-Grunwald-Giemsa (Merck, Darmstadt, Germany).

This study was approved by the Local Ethics Committee VUmc. Date of approval: December 5, 2000 (file number TJFS/bz2568a).

\section{In situ thymidylate synthase inhibition assay}

The TSIA was used to measure in vitro efficacy of MTX to inhibit TS, which is known to determine cytotoxicity in MTX exposed cells. Inhibition of TS was determined in whole cells by measuring the TS-catalyzed conversion of ${ }^{3} \mathrm{H}$-dUMP to dTMP and ${ }^{3} \mathrm{H}_{2} \mathrm{O}$, as described previously [34]. Two conditions were used: a continuous $21-\mathrm{h}$ incubation or a short 3-h exposure, followed by an 18-h drug-free period. Data are expressed as the concentration 
of MTX necessary to inhibit $50 \%$ of the TS activity $\left(\mathrm{TSI}_{50}\right.$ ) compared to the controls incubated without MTX (in triplicate) [34, 53].

\section{MTX accumulation and polyglutamylation}

Ten million leukemic cells were incubated for $24 \mathrm{~h}$ with $1 \mu \mathrm{M}\left[3^{\prime}, 5^{\prime}, 7-{ }^{3} \mathrm{H}\right]-\mathrm{MTX}$ (Moravek Biochemicals; final specific activity $2 \mathrm{Ci} / \mathrm{mmol}$ ) in a 5 -ml culture medium, as described previously [17]. After washing, samples were counted for radioactivity, cell number, and viability. The remaining suspension was centrifuged, and the cell pellet was used for measurement of polyglutamates using high-performance liquid chromatography on an anion exchange column as described previously $[17,53]$. The data are expressed as pmol MTX-Glu $/ 10^{9}$ cells. Total MTX polyglutamates included MTX associated with 1 up to 6 glutamate residues, while long-chain MTX polyglutamates corresponded to MTX associated with 4 up to 6 glutamate residues.

\section{RNA extraction, reverse transcription, and quantitative PCR assay}

Freshly isolated cells were washed twice in RPMI (Gibco) containing $2 \%$ fetal calf serum, followed by lysis in $1 \mathrm{ml}$ RNAzol. Next, the samples were frozen in liquid nitrogen and stored at $-80{ }^{\circ} \mathrm{C}$ until further processing. RNA extraction was performed according to manufacturer's instructions with previously described adjustments [35]. Competitive template PCR was performed as described previously [35].

\section{FPGS activity assay}

The FPGS activity assay was performed as described previously [17]. Briefly, the reaction was carried out in crude cell extracts employing a 2-h incubation with a final concentration of $250 \mu \mathrm{M}$ MTX and $4 \mu \mathrm{mM}\left[{ }^{3} \mathrm{H}\right]-\mathrm{L}$ glutamic acid at $37^{\circ} \mathrm{C}$, which was next terminated with ice-cold glutamic acid. The resulting MTX- $\left[{ }^{3} \mathrm{H}\right]-\mathrm{Glu}_{2}$ was separated from unreacted $\left[{ }^{3} \mathrm{H}\right]$-L-glutamic acid by reverse-phase column chromatography and quantified as described previously [17].

\section{Statistical analysis}

All statistical analyses were performed using the IBM SPSS Statistics 20 software. The Mann-Whitney $U$ test was used to compare the levels of MTX resistancerelated variables between different subgroups of ALL patients, while Spearman's Rho test and linear regression were applied to assess correlations. Kaplan-Meier analysis and Cox regression were used in the analysis of EFS as well as OS of the patients. The cut-off values for survival analysis were selected based on literature (clinical factors) [2, 40, 41, 49, 50]. For MTX-related variables, if the distribution was bimodal, we chose the cut-off value midway between the two modes of the distributions; otherwise, we used the median as a cut-off. KaplanMeier analysis and Cox regression were used for testing associations between MTX resistance-related variables and event-free (defined as time from complete remission to an event) as well as overall survival of the patients. Events considered in event-free survival were relapse and death. MTX resistance-related variables which showed significant impact on survival in the univariate analysis $(P<0.05$ at two-sided testing) were added to a multivariate Cox regression model with identified prognostic clinical factors in order to assess their added prognostic value. As different protocols were used with different patients, additional analyses were performed in which we corrected for the protocol used by including protocol as an additional independent variable in the Cox regression model.

\section{Additional file}

Additional file 1: Patient characteristics and supplemental survival analysis. Table S1. Clinical characteristics of pediatric ALL patients included in this study. Table S2. Results of univariate Cox regression model of MTX resistance related variables in relation to overall survival. Table S3. Treatment outcome (EFS) in the whole cohort according to presenting features (not corrected for the treatment protocol). Table S4. Treatment outcome (EFS) in the whole cohort according to presenting features (corrected for the treatment protocol). Table S5. Results of multivariate Cox regression model of MTX resistance related variables in relation to event-free survival. Table S6. Results of multivariate Cox regression model of MTX resistance related variables in relation to overall survival.

\section{Competing interests}

The authors declare that they have no competing interests.

\section{Authors' contributions}

JC was the principal investigator and takes primary responsibility for the paper; GE, KS, and ES provided patient samples and clinical data; AW, NLW, PMV, and BD performed the research; JC, GJLK, GJ, GJP, and YGA designed the research; AW wrote the paper; JC, GJLK, GJ, GJP, GE, KS, ES, NLW, PMV, BD, YGA, and RP edited the paper. All authors read and approved the final manuscript.

\section{Acknowledgements}

The authors would like to thank Marianne Rots and Michael Dworzak for their data contributions. This study was supported by KiKa (Children cancer-free). Y. $\mathrm{G}$. Assaraf is a recipient of a visiting professor fellowship of the Royal Netherlands Academy of Arts and Sciences.

\section{Author details}

${ }^{1}$ Department of Pediatric Oncology/Hematology, VUmc Cancer Center Amsterdam, VU University Medical Center, Room CCA 4.28, De Boelelaan 1117, 1081 HV Amsterdam, The Netherlands. ${ }^{2}$ Department of Hematology, VU University Medical Center, Amsterdam, The Netherlands. ${ }^{3}$ Department of Medical Oncology, VU University Medical Center, Amsterdam, The Netherlands. ${ }^{4}$ Department of Epidemiology and Biostatistics, VU University Medical Center, Amsterdam, The Netherlands. ${ }^{5}$ Department of

Rheumatology, VU University Medical Center, Amsterdam, The Netherlands. ${ }^{6}$ Department of Pediatric Hematology/Oncology, University Medical Center Hamburg-Eppendorf, Hamburg, Germany. ${ }^{7}$ Institute of Clinical Medicine, University of Copenhagen, Copenhagen, Denmark. ${ }^{8}$ Department of Pediatrics and Adolescent Medicine, University Hospital Rigshospitalet, Copenhagen, Denmark. 'Dutch Childhood Oncology Group (DCOG), The Hague, The Netherlands. ${ }^{10}$ Princess Máxima Center for Pediatric Oncology, Utrecht, The Netherlands. ${ }^{11}$ Department of Biology, Technion-Israel Institute of Technology, Haifa, Israel. 
Received: 9 March 2015 Accepted: 19 May 2015

Published online: 29 May 2015

\section{References}

1. Pui CH, Mullighan CG, Evans WE, Relling MV. Pediatric acute lymphoblastic leukemia: where are we going and how do we get there? Blood. 2012;120:1165-74.

2. Escherich G, Horstmann MA, Zimmermann M, Janka-Schaub GE. Cooperative study group for childhood acute lymphoblastic leukaemia (COALL): long-term results of trials 82,85,89,92 and 97. Leukemia. 2010;24:298-308.

3. Einsiedel HG, Von Stackelberg A, Hartmann R, Fengler R, Schrappe M, Janka-Schaub G, et al. Long-term outcome in children with relapsed ALL by risk-stratified salvage therapy: results of trial acute lymphoblastic leukemia-relapse study of the Berlin-Frankfurt-Munster Group 87. J Clin Oncol. 2005;23:7942-50.

4. Pui CH, Relling MV, Downing JR. Acute lymphoblastic leukemia. N Engl J Med. 2004;350:1535-48.

5. Meijerink JPP, den Boer ML, Pieters R. New genetic abnormalities and treatment response in acute lymphoblastic leukemia. Semin Hematol. 2009;46:16-23.

6. Bertino J. Karnofsky memorial lecture. Ode to methotrexate. J Clin Oncol. 1993;11:5-14.

7. Stokstad ELR. Historical perspectives on key advances in the biochemistry and physiology of folates. In: Picciano MF, Stokstad ELR, Gregory JF, editors. Evaluation of Folic Acid Metabolism in Health and Disease. New York, NY: Wiley-Liss; 1990. p. 1-21.

8. Cheok MH, Lugthart S, Evans WE. Pharmacogenomics of acute leukemia. Annu Rev Pharmacol Toxicol. 2006:46:317-53.

9. Assaraf YG. Molecular basis of antifolate resistance. Cancer Metastasis Rev. 2007;26:153-81.

10. Allegra CJ, Hoang K, Yeh GC, Drake JC, Baram J. Evidence for direct inhibition of de novo purine synthesis in human MCF-7 breast cells as a principal mode of metabolic inhibition by methotrexate. J Biol Chem. 1987:262:13520-6.

11. Allegra CJ, Chabner BA, Drake JC, Lutz R, Rodbard D, Jolivet J. Enhanced inhibition of thymidylate synthase by methotrexate polyglutamates. J Biol Chem. 1985;260:9720-6.

12. Baggott JE, Vaughn WH, Hudson BB. Inhibition of 5-aminoimidazole-4carboxamide ribotide transformylase, adenosine deaminase and 5'-adenylate deaminase by polyglutamates of methotrexate and oxidized folates and by 5-aminoimidazole-4-carboxamide riboside and ribotide. Biochem J. 1986;236:193-200

13. Gonen N, Assaraf YG. Antifolates in cancer therapy: structure, activity and mechanisms of drug resistance. Drug Resist Updat. 2012;15:183-210.

14. Hooijberg JH, Broxterman HJ, Kool M, Assaraf $Y G$, Peters GJ, Noordhuis $P$, et al. Antifolate resistance mediated by the multidrug resistance proteins MRP1. Cancer Res. 1999;59:2532-5.

15. Masson E, Relling MV, Synold TW, Liu Q, Schuetz JD, Sandlund JT, et al. Accumulation of methotrexate polyglutamates in lymphoblasts is a determinant of antileukemic effects in vivo. J Clin Invest. 1996;97:73-80.

16. Kager L, Cheok M, Yang W, Zaza G, Cheng Q, Panetta JC, et al. Folate pathway gene expression differs in subtypes of acute lymphoblastic leukemia and influences methotrexate pharmacodynamics. J Clin Invest. 2005:115:110-7.

17. Rots MG, Pieters R, Peters GJ, Noordhuis P, van Zantwijk CH, Kaspers GJ, et al. Role of folylpolyglutamate synthetase and folylpolyglutamate hydrolase in methotrexate accumulation and polyglutamylation in childhood leukemia. Blood. 1999;93:1677-83.

18. Cheok MH, Pottier N, Kager L, Evans WE. Pharmacogenetics in acute lymphoblastic leukemia. Semin Hematol. 2009:46:39-51.

19. Rothem L, Aronheim A, Assaraf YG. Alterations in the expression of transcription factors and the reduced folate carrier as a novel mechanism of antifolate resistance in human leukemia cells. J Biol Chem. 2003;278:8935-41.

20. Rothem L, Stark M, Kaufman Y, Mayo L, Assaraf YG. Reduced folate carrie gene silencing in multiple antifolate-resistant tumor cell lines is due to a simultaneous loss of function of multiple transcription factors but not promoter methylation. J Biol Chem. 2004;279:374-84.

21. Kaufman Y, Ifergan I, Rothem L, Jansen G, Assaraf YG. Coexistence of multiple mechanisms of PT523 resistance in human leukemia cells harboring 3 reduced folate carrier alleles: transcriptional silencing, inactivating mutations, and allele loss. Blood. 2006;107:3288-94.
22. Schmiegelow K. Advances in individual prediction of methotrexate toxicity: a review. Br J Haematol. 2009;146:489-503.

23. De Jonge R, Hooijberg JH, van Zelst BD, Jansen $G$, van Zantwijk $C H$, Kaspers GJL, et al. Effect of polymorphisms in folate-related genes on in vitro methotrexate sensitivity in pediatric acute lymphoblastic leukemia. Blood. 2005;106:717-20.

24. Gregers J, Christensen IJ, Dalhoff K, Lausen B, Schroeder H, Rosthoej S, et al. The association of reduced folate carrier $80 \mathrm{G}>\mathrm{A}$ polymorphism to outcome in childhood acute lymphoblastic leukemia interacts with chromosome 21 copy number. Blood. 2010;115:4671-7.

25. Mauritz R, Peters GJ, Priest DG, Assaraf YG, Drori S, Kathmann I, et al. Multiple mechanisms of resistance to methotrexate and novel antifolates in human CCRF-CEM leukemia cells and their implications for folate homeostasis. Biochem Pharmacol. 2002;63:105-15.

26. Zhao R, Titus S, Gao F, Moran RG, Goldman ID. Molecular analysis of murine leukemia cell lines resistant to 5, 10-dideazatetrahydrofolate identifies several amino acids critical to the function of folylpolyglutamate synthetase. J Biol Chem. 2000;275:26599-606.

27. Liani E, Rothem L, Bunni MA, Smith CA, Jansen G, Assaraf YG. Loss of folylpoly-gamma-glutamate synthetase activity is a dominant mechanism of resistance to polyglutamylation-dependent novel antifolates in multiple human leukemia sublines. Int J cancer. 2003;103:587-99.

28. Stark M, Wichman C, Avivi I, Assaraf YG. Aberrant splicing of folylpolyglutamate synthetase as a novel mechanism of antifolate resistance in leukemia. Blood. 2009;113:4362-9.

29. Whitehead VM, Vuchich MJ, Lauer SJ, Mahoney D, Carroll AJ, Shuster JJ, et al. Accumulation of high levels of methotrexate polyglutamates in lymphoblasts from children with hyperdiploid (greater than 50 chromosomes) B-lineage acute lymphoblastic leukemia: a Pediatric Oncology Group study. Blood. 1992;80:1316-23.

30. Belkov VM, Krynetski EY, Schuetz JD, Yanishevski Y, Masson E, Raimondi S, et al. Mechanism for ploidy but not lineage differences in methotrexate mechanism for ploidy but not lineage differences in methotrexate accumulation. Blood. 1999;93:1643-50.

31. Dervieux T, Hancock M, Evans W, Pui C, Relling M. Effect of methotrexate polyglutamates on thioguanine nucleotide concentrations during continuation therapy of acute lymphoblastic leukemia with mercaptopurine. Leukemia. 2002;16:209-12.

32. Schmiegelow K, Nielsen S, Frandsen TL, Nersting J. Mercaptopurine/ methotrexate maintenance therapy of childhood acute lymphoblastic leukemia: clinical facts and fiction. J Pediatr Hematol Oncol. 2014;36:503-17.

33. Lennard L, Lilleyman JS, Van Loon J, Weinshilboum RM. Genetic variation in response to 6-mercaptopurine for childhood acute lymphoblastic leukaemia. Lance. 1990;336:225-9.

34. Rots MG, Pieters R, Kaspers GJ, van Zantwijk CH, Noordhuis P, Mauritz R, et al. Differential methotrexate resistance in childhood T- versus common/preB-acute lymphoblastic leukemia can be measured by an in situ thymidylate synthase inhibition assay, but not by the MTT assay. Blood. 1999;93:1067-74.

35. Rots M, Willey J, Jansen G, van Zantwijk CH, Noordhuis P, DeMuth J, et al. mRNA expression levels of methotrexate resistance-related proteins in childhood leukemia as determined by a standardized competitive template-based RT-PCR method. Leukemia. 2000;14:2166-75.

36. Synold TW, Relling MV, Boyett JM, Rivera GK, Sandlund JT, Mahmoud H, et al. Blast cell methotrexate-polyglutamate accumulation in vivo differs by lineage, ploidy, and methotrexate dose in acute lymphoblastic leukemia. J Clin Invest. 1994;94:1996-2001.

37. Whitehead VM, Rosenblatt DS, Vuchich MJ, Shuster JJ, Witte A, Beaulieu D. Accumulation of methotrexate and methotrexate polyglutamates in lymphoblasts at diagnosis of childhood acute lymphoblastic leukemia: a pilot prognostic factor analysis. Blood. 1990;76:44-9.

38. Whitehead VM, Shuster JJ, Vuchich MJ, Mahoney DH, Lauer SJ, Payment C, et al. Accumulation of methotrexate and methotrexate polyglutamates in lymphoblasts and treatment outcome in children with B-progenitor-cell acute lymphoblastic leukemia: a Pediatric Oncology Group study. Leukemia. 2005;19:533-6.

39. Levy AS, Sather HN, Steinherz PG, Sowers R, La M, Moscow JA, et al. Reduced folate carrier and dihydrofolate reductase expression in acute lymphocytic leukemia may predict outcome: a Children's Cancer Group Study. J Pediatr Hematol Oncol. 2003;25:688-95. 
40. Kamps WA, van der Pal-de Bruin KM, Veerman AJP, Fiocco M, Bierings M, Pieters R. Long-term results of Dutch Childhood Oncology Group studies for children with acute lymphoblastic leukemia from 1984 to 2004. Leukemia. 2010;24:309-19.

41. Harms DO, Janka-Schaub GE. Co-operative study group for childhood acute lymphoblastic leukemia (COALL): long-term follow-up of trials 82, 85, 89 and 92. Leukemia. 2000;14:2234-9.

42. Jansen G, Mauritz R, Drori S, Sprecher H, Kathmann I, Bunni M, et al. A structurally altered human reduced folate carrier with increased folic acid transport mediates a novel mechanism of antifolate resistance. J Biol Chem. 1998:273:30189-98.

43. Galpin AJ, Schuetz JD, Masson E, Yanishevski Y, Synold TW, Barredo JC, et al. Differences in folylpolyglutamate synthetase and dihydrofolate reductase expression in human B-lineage versus T-lineage leukemic lymphoblasts: mechanisms for lineage differences in methotrexate polyglutamylation and cytotoxicity. Mol Pharmacol. 1997;52:155-63.

44. Wojtuszkiewicz A, Assaraf YG, Maas M, Kaspers G, Jansen G, Cloos J. Pre-mRNA splicing in cancer: the relevance in oncogenesis, treatment and drug resistance. Expert Opin Drug Metab Toxicol. 2015;11:673-89.

45. Roy K, Egan M, Sirlin S, Sirotnak F. Posttranscriptionally mediated decreases in folylpolyglutamate synthetase gene expression in some folate analogue-resistant variants of the L1210 Cell. J Biol Chem. 1997;272:6903-8.

46. Assaraf YG. The role of multidrug resistance efflux transporters in antifolate resistance and folate homeostasis. Drug Resist Updat. 2006:9:227-46.

47. Leclerc GJ, Sanderson C, Hunger S, Devidas M, Barredo JC.

Folylpolyglutamate synthetase gene transcription is regulated by a multiprotein complex that binds the TEL-AML1 fusion in acute lymphoblastic leukemia. Leuk Res. 2010:34:1601-9.

48. Leclerc GJ, Mou C, Leclerc GM, Mian AM, Barredo JC. Histone deacetylase inhibitors induce FPGS mRNA expression and intracellular accumulation of long-chain methotrexate polyglutamates in childhood acute lymphoblastic leukemia: implications for combination therapy. Leukemia. 2010;24:552-62.

49. Veerman AJ, Kamps WA, van den Berg H, van den Berg E, Bökkerink JPM, Bruin MCA, et al. Dexamethasone-based therapy for childhood acute lymphoblastic leukaemia: results of the prospective Dutch Childhood Oncology Group (DCOG) protocol ALL-9 (1997-2004). Lancet Oncol. 2009;10:957-66.

50. Schmiegelow K, Forestier E, Hellebostad M, Heyman M, Kristinsson J, Söderhäll S, et al. Long-term results of NOPHO ALL-92 and ALL-2000 studies of childhood acute lymphoblastic leukemia. Leukemia. 2010;24:345-54.

51. Pieters R, Loonen AH, Huismans DR, Broekema G, Dirven M, Heyenbrok M, et al. In vitro drug sensitivity of cells from children with leukemia using the MTT assay with improved culture conditions. Blood. 1990;76:2327-36.

52. Kaspers GJ, Veerman AJ, Pieters R, Broekema GJ, Huismans DR, Kazemier KM, et al. Mononuclear cells contaminating acute lymphoblastic leukaemic samples tested for cellular drug resistance using the methyl-thiazol-tetrazolium assay. Br J Cancer. 1994;70:1047-52.

53. Mauritz R, Bekkenk M, Rots M, Pieters R, Mini E, van Zantwijk CH, et al. Ex vivo activity of methotrexate versus novel antifolate inhibitors of dihydrofolate reductase and thymidylate synthase against childhood leukemia cells. Clin Cancer Res. 1998:4:2399-410.

\section{Submit your next manuscript to BioMed Central and take full advantage of:}

- Convenient online submission

- Thorough peer review

- No space constraints or color figure charges

- Immediate publication on acceptance

- Inclusion in PubMed, CAS, Scopus and Google Scholar

- Research which is freely available for redistribution

Submit your manuscript at www.biomedcentral.com/submit 